\title{
Effects of different extraction methods on the extraction yield, degradation of bixin and formation of harmful volatile compounds in the extracts from annatto seeds
}

\author{
${ }^{1, *}$ Chuyen, H.V. and ${ }^{2}$ Eun, J.B. \\ ${ }^{1}$ Faculty of Food Science and Technology, Thu Dau Mot University, Binh Duong Province, Vietnam \\ ${ }^{2}$ Department of Food Science and Technology, Chonnam National University, Gwangju, Korea
}

\section{Article history:}

Received: 7 January 2021

Received in revised form: 12

March 2021

Accepted: 29 April 2021

Available Online: 7

November 2021

Keywords:

Bixin,

Toluene,

$m$-xylene,

Degradation,

Extraction yield

DOI:

https://doi.org/10.26656/fr.2017.5(6).017

\begin{abstract}
Annatto is one of the most common natural colorants used in the food industry. However, the degradation of bixin (principle colour component) during the manufacturing and storage of annatto leads to the formation of undesirable volatile compounds which are harmful to human health. The aim of this study was to reduce the amount of undesirable volatile compounds while remain a sufficient extraction yield of bixin in annatto extracts. Bixin from annatto seeds was extracted using soybean oil at $120^{\circ} \mathrm{C}$, sodium hydroxide solution at $50^{\circ} \mathrm{C}$ and acetone with a Soxhlet extractor. The extraction yield and the degradation of bixin in annatto extracts during the extraction processes were investigated and the formation of harmful volatile compounds including toluene and $m$-xylene in the extracts was analysed using a gas chromatography (GC) system equipped with a flame ionization detector (FID). The extraction with acetone resulted in the highest bixin yield, followed by extraction with sodium hydroxide. Bixin extraction yield of the extraction with soybean oil was the lowest and decreased gradually after 40 mins of the extraction. Losses of bixin by the extractions with acetone and sodium hydroxide were low while the extraction with soybean oil caused significant degradation of bixin. All three methods produced negligible amounts of toluene. However, the concentration of $m$-xylene in the acetone extracts was very high and remained unchanged during the extraction while sodium hydroxide extract contained a low level of this compound. Thus, the extraction method using sodium hydroxide solution is recommended for recovering pigment from annatto seeds to minimize the risk of harmful volatile compounds in annatto products.
\end{abstract}

\section{Introduction}

Annatto is a natural colorant obtained from the seed coat of Bixa orellana L., a tropical shrub. It creates a range of colours from yellow, orange to red depending on the concentration and principle colour compound of annatto solution. Annatto seeds and annatto extracts have been used in foods for hundreds of years in South America (the major source of annatto production), Africa, Europe, and North America. Annatto is one of the most frequently used natural colorants in the food industry and is used in a variety of foods such as meat and fish products, soft drinks and confectioneries. The high colour intensity and biological properties of annatto pigment, including its antioxidant activity and anticancer effects, have attracted the consideration of many researchers. For example, the antioxidant activity of annatto pigment was reported by its ability to inhibit hydroperoxide formation of triglycerides (Haila et al.,
1996). A study by Montenegro et al. (2004) also showed that bixin, the principal constituent of annatto, is an efficient quencher of singlet molecular oxygen. Junior et al. (2005) demonstrated that annatto pigment has antigenotoxic potential by protecting against DNA damage in Escherichia coli cells induced by UV radiation, hydrogen peroxide, and superoxide anion as well as antimutagenic activity based on a Salmonella mutagenicity test. For these reasons, annatto has significant economic importance and is one of the most frequently used natural colorants in the food industry.

More than $80 \%$ of the total pigment content in annatto seed coat is composed of bixin (Preston and Rickard, 1980). As a carotenoid, bixin (methyl hydrogen $9^{\prime}$-cis-6,6'-diapocarotene-6,6'-dioate) is very susceptible to processing and storage conditions such as temperature, light and oxygen. Many studies have concentrated on the degradation of bixin during storage and the stability of 
bixin added in food products (Prabhakara Rao et al., 2005; Scotter, 2009; Balaswamy et al., 2012). The stability of annatto solution extracted with chloroform upon exposure to light, air, anti-oxidants and prooxidants was described by Najar et al. (1988). In their study, the most destructive agent was light, followed by the pro-oxidant, benzoyl peroxide. The light was also demonstrated to have a stronger effect than the temperature on the stability of bixin in annatto powder and annatto oleoresin in a later study (Balaswamy et al., 2006). Glória et al. (1995) reported a significant effect of water activity on the stability of bixin in annatto extract, wherein bixin was observed to be more stable at intermediate/higher water activities. The effects of processing conditions on the stability of annatto added to cakes, chegodis, biscuits, and fried rice were studied by Prabhakara Rao et al. (2005). They found no effect of microwaves on bixin when preparing biscuits while a significant loss of bixin (65\%) was observed in the processing of deep fat fried snack (chegodis).

In addition to the negative effect on the colour intensity of annatto pigment, the degradation of bixin also produces undesirable substances for food use, such as $m$-xylene, toluene and toluic acid (McKeown, 1963; Scotter et al., 2001). Several studies have been carried out to investigate the formation and composition of thermally degraded compounds in different annatto formulations (Scotter, 1995; Scotter et al., 1998; Scotter et al., 2000). $m$-Xylene was found in the annatto samples at a concentration up to $200 \mathrm{mg} / \mathrm{kg}$ and the highest content of toluene in the samples was $12 \mathrm{mg} / \mathrm{kg}$ (Scotter et al., 2000). In a study by Hoang et al. (2012), a combination of extraction using sodium hydroxide solution followed by extraction with soybean was suggested for reducing the content of $m$-xylene and toluene in the extracts compared to the uses of the single solvents.

Regarding the recovery of pigment from annatto seeds for food colouring, a number of studies have been done to improve the extraction yield of bixin using various solvents and extraction techniques. A study using ultrasound-assisted extraction found that the extraction using chloroform at $72.7^{\circ} \mathrm{C}$ using ultrasound at a duty cycle of 0.8 secs for 7.25 min results in the highest yield of bixin (Yolmeh et al., 2014). Many studies using microwave-assisted extraction combined with the application of mathematical models to optimize the extraction conditions were applied for maximizing bixin recovery from annatto seeds (Soumya et al., 2010; Sinha et al., 2013; Quintero Quiroz et al., 2019). The literature also showed that among a variety of investigated solvents for recovering pigment from annatto seeds, vegetable oil, sodium hydroxide solution and acetone are the promising solvents due to their availability and low risks to human health compared to the others (Yolmeh et al., 2014; Rahmalia et al., 2015; Taham et al., 2015). In addition, although the presence of undesirable volatile compounds in annatto products have been mentioned in a few studies, the effects of different extraction conditions, extraction techniques and the correlation between the degradation of bixin and the formation of those compounds during the extraction processes are limited.

In the present study, the extraction yield, degradation of bixin and the formation of toluene and $m$-xylene during three extraction processes using soybean oil, acetone, and sodium hydroxide solution were investigated to determine suitable extraction conditions and methods for reducing the content of volatile compounds in annatto extracts while achieving high pigment extraction efficiency.

\section{Materials and methods}

\subsection{Materials}

Annatto seeds and soybean oil were purchased from a local market. Acetone and sodium hydroxide were supplied by Dea Jung Company (Busan, South Korea); pentane was provided by Kanto Chemical Company (Tokyo, Japan); bixin ( $\geq 90 \%)$, tetrahydrofuran ( $\geq 99 \%$ ), ethylbenzene (99.8\%), toluene (99.8\%), $m$-xylene ( $\geq 99 \%$ ), and spectrophotometric grade $o$-xylene ( $\geq 99 \%$ ) were obtained from Sigma-Adrich (Seoul, South Korea). The other reagents were of recognized analytical grade.

\subsection{Methods of bixin extraction and bixin determination}

Bixin content in annatto seeds was determined by repeated extraction of the seeds with chloroform in the dark up to total extraction of the colour (Balaswamy et al., 2006). Bixin in annatto seeds was extracted by three methods. Extraction by vegetable oil was carried out by submerging $5 \mathrm{~g}$ of annatto seeds in $20 \mathrm{~mL}$ of vegetable oil at $120^{\circ} \mathrm{C}$ and stirring for 120 mins (Preston and Rickard, 1980). Soxhlet apparatus was applied in the extraction using acetone for 120 mins (Balaswamy et al., 2006). In the extraction using sodium hydroxide solution, $5 \mathrm{~g}$ of annatto seeds was submerged and stirred in $20 \mathrm{~mL}$ of $0.1 \mathrm{~N} \mathrm{NaOH}$ solution at $50^{\circ} \mathrm{C}$ for $120 \mathrm{mins}$ (Shuhama et al., 2003). Bixin contents in the extracts of these methods were measured every 20 mins.

Degradation of bixin was investigated by measuring the decrease in the content of bixin of the solutions which were added a fixed amount of standard bixin and then treated with the same conditions as those of the extraction processes. To investigate the loss of bixin during extraction with vegetable oil, $1 \mathrm{~mL}$ of vegetable oil contained standard bixin was added to $19 \mathrm{~mL}$ of pure 
vegetable oil at $120^{\circ} \mathrm{C}$ in a stirring beaker for $120 \mathrm{~min}$. Similarly, $1 \mathrm{~mL}$ of $\mathrm{NaOH}$ solution contained standard bixin was added to a stirring beaker containing $19 \mathrm{~mL}$ of $\mathrm{NaOH}$ solution at $50^{\circ} \mathrm{C}$ for 120 mins to measure the degradation of bixin. Determination of the amount of bixin lost in acetone extraction was carried out by adding $1 \mathrm{~mL}$ of acetone contained standard bixin to a Soxhlet extractor containing acetone, which was then operated for 120 mins. Bixin content in the solutions of these processes was sampled every 20 mins to determine the bixin degradation.

The content of bixin in the extracts was determined by measuring the absorbance of the bixin solutions using a spectrophotometer at $487 \mathrm{~nm}$ (Smith, 2006). Briefly, 1 $\mathrm{mL}$ of bixin extract was dissolved in $10 \mathrm{~mL}$ of tetrahydrofuran in a $100 \mathrm{~mL}$-volumetric flask, followed by dilution with acetone to achieve a solution having absorbance in the range of 0.2-1.0. The absorbance of the diluted solution was measured in a $1 \mathrm{~cm}$ cuvette using a spectrophotometer (Optizen 2120UV, Mecasys Co. Ltd, South Korea) at $487 \mathrm{~nm}$. The concentration of bixin in solution was calculated based on an extinction coefficient $\left(\mathrm{E}_{1 \%}{ }^{\mathrm{lcm}}\right)$ of 3090 .

\subsection{Gas chromatography $(G C)$ analysis}

Sample preparation: $1 \mathrm{~mL}$ of extract was accurately transferred into a Falcon tube, after which $m$-xylene and toluene were isolated by pentane containing $o$-xylene recovery standard $(20 \mathrm{mg} / \mathrm{L})$ according to Scotter et al. (2000). Pentane portion, after being washed by water and dried by sodium sulphate anhydrous, was added with internal standard solution (ethylbenzene in pentane) and diluted to deliver a solution containing $10 \mathrm{mg} / \mathrm{L}$ of ethylbenzene. This solution was then analysed by a GC system.

GC system: The system comprised an HP 6890 series GC (Hewlett Packard Co. Ltd, USA) fitted with a capillary column Omegawax 320 (30 m length, $0.32 \mathrm{~mm}$ inner diameter, and $25 \mu \mathrm{m}$ film thickness). The helium carrier gas was maintained at $19 \mathrm{~cm} / \mathrm{s}$. Split mode injection (20:1) was used at a temperature of $250{ }^{\circ} \mathrm{C}$ with an injection volume of $4 \mu \mathrm{L}$. A flame ionization detector at $250^{\circ} \mathrm{C}$ was used for the detection of volatile compounds. The column temperature was programmed to increase from $60-75^{\circ} \mathrm{C}$ at $15^{\circ} \mathrm{C} / \mathrm{min}$ and then raised to $90^{\circ} \mathrm{C}$ at $3^{\circ} \mathrm{C} / \mathrm{min}$.

Calibration was established by injection of mixed standards prepared in pentane with a range of concentrations from 1 to $20 \mathrm{mg} / \mathrm{L}$ and containing a fixed amount of ethylbenzene internal standard at $10 \mathrm{mg} / \mathrm{L}$. The detector response of each component was normalized against ethylbenzene, and calibration lines were constructed using response ratios. The detector response was linear for each component over this range with the same $R$-squared value $\left(R^{2}=0.998\right)$.

\subsection{Data analysis}

The results are expressed as the means \pm standard deviations, and the statistical significance was analyzed by one-way analysis of variance (ANOVA). LSD tests were used for comparisons amongst values. Differences were considered to be significantly different at $p<0.05$.

\section{Results and discussion}

\subsection{Extraction yield}

The yields of bixin extracted by the three extraction methods are shown in Figure 1. The extraction with acetone resulted in the highest bixin yield compared to the other methods. A very high yield of bixin (44.0\%, equivalent to $5.9 \mathrm{mg} / \mathrm{g}$ dried seeds) was obtained in 20 mins of the acetone extraction. The yield then rose rapidly to $81.3 \%$ (equivalent to $10.9 \mathrm{mg} / \mathrm{g}$ dried seeds) at 120 mins of the extraction. Bixin yield at 140 mins of the extraction with acetone was found to be higher than that at 120 mins but the difference was not statistically significant $(p<0.05)$. Thus, the duration of $2 \mathrm{hrs}$ was selected for the investigation and comparison of the extraction methods. Extraction with soybean oil also produced a high yield of bixin at the beginning of the process. However, the amount of extracted bixin increased only slightly from $28.3 \%$ at 20 mins to $30.2 \%$ at $40 \mathrm{mins}$, followed by a gradual decrease to $24.7 \%$ (equivalent to $3.3 \mathrm{mg} / \mathrm{g}$ dried seeds) at $120 \mathrm{mins}$ of extraction. These results are consistent with a report of Barnett (1957), who found a very low extraction yield of pigment in the production of oil-soluble annatto (less than $30 \%$ ). Although the bixin yield of extraction with sodium hydroxide solution was only $23.6 \%$ (equivalent to $3.1 \mathrm{mg} / \mathrm{g}$ dried seeds) after $20 \mathrm{mins}$, it increased steadily during the process and reached $45.4 \%$ (equivalent to $6.1 \mathrm{mg} / \mathrm{g}$ dried seeds) at the end of

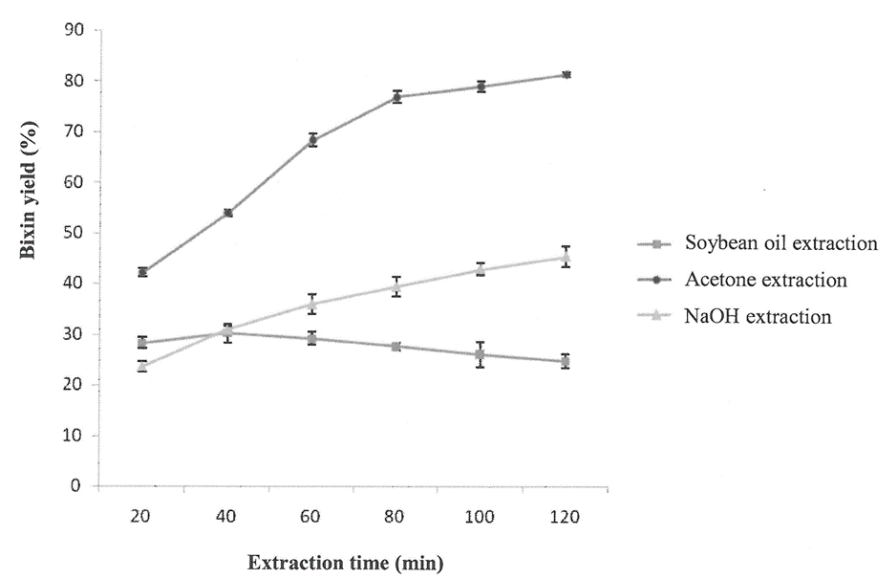

Figure 1. Effect of extraction time on the yield of bixin extracted with soybean oil, acetone and sodium hydroxide solution

C 2021 The Authors. Published by Rynnye Lyan Resources 
extraction.

In the extraction with acetone, annatto seed was washed continuously by pure acetone distilled by the Soxhlet extractor. Thus, a high concentration gradient between the seeds and the solvent was maintained during the extraction while the concentration gradients in the other extractions were being lowered by the increasing content of bixin in the solutions. The high concentration gradient accelerated the diffusion of colour from the material into the extraction solvent and thereby resulted in the highest bixin yield in acetone compared to vegetable oil and sodium hydroxide solution.

In comparison to the results of the previous studies, the obtained bixin extraction yield by the processes using in this study was significantly higher than that of the microwave-assisted extraction (Shinha et al., 2014; Quintero Quiroz et al., 2019) and ultrasound-assisted extraction (Yolmeh et al., 2014). The lower extraction yield reported in the previous studies may be caused by the use of improper solvents (water, ethanol and chloroform) for the extraction of annatto pigment. Thus, despite using advanced extraction techniques, the selection of suitable solvents plays an important role in the extraction efficiency of bixin from annatto seeds.

\subsection{Degradation of bixin}

Figure 2 shows the losses of bixin during extractions using vegetable oil, acetone, and sodium hydroxide solution. The loss of bixin during extraction with vegetable oil was $29.7 \%$ after only $20 \mathrm{mins}$ and rose sharply to $63.4 \%$ at the end. The high degradation of bixin in this method can be explained by the use of a very high temperature $\left(120^{\circ} \mathrm{C}\right)$. This result is in agreement with a report by (Reith and Gielen, 1971), which showed that degraded yellow products of bixin decomposition $\left(\mathrm{C}_{17}\right.$ species $)$ constituted up to $40 \%$ of commercial oil-soluble annatto products. In contrast, amounts of degraded bixin during extractions with acetone and sodium hydroxide solution were very low

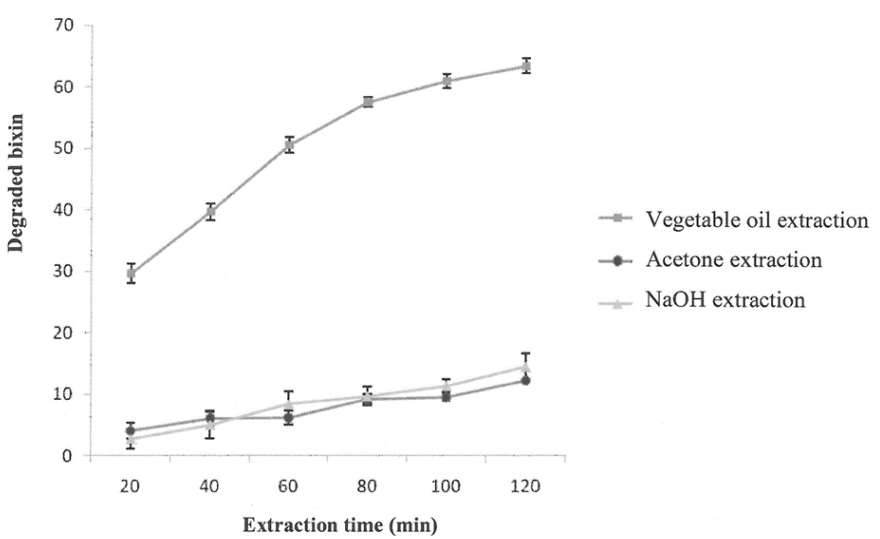

Figure 2. Degradation of bixin during the extractions with soybean oil, acetone and sodium hydroxide solution and increased slowly. Percentages of bixin degraded in extractions with acetone and sodium hydroxide solution were $4.1 \%$ and $2.7 \%$ after $20 \mathrm{mins}$, and $12.3 \%$ and $14.5 \%$ at the end, respectively. Although extraction with sodium hydroxide solution was carried out at a lower temperature than that with acetone, the loss of bixin was not significantly different and even higher at the ending period of the process. This result indicates the effect of water activity on the stability of bixin as shown in a study by Glória et al. (1995).

\subsection{Total amount of bixin released from annatto seeds into solutions}

The total amounts of bixin, which were transferred from annatto seeds into the extracts by the three methods, are shown in Figure 3. After adding the amounts of obtained and degraded bixin, the factual percentages of bixin transferred from the seed coat of annatto into acetone extracts and soybean oil extracts were very high. The total amount of bixin freed from annatto seed by extraction with acetone was the highest compared to the other methods, it was $44 \%$ after 20 mins and rose to $92.7 \% \%$ (equivalent to $12.4 \mathrm{mg} / \mathrm{g}$ dried seeds) at 120 mins This high extraction percentage was due to the strong solubility of bixin in acetone as well as the continuous washing of the process of annatto seeds in a pure solvent in the Soxhlet extractor. The percentage of bixin extracted with soybean oil was also significantly higher than that extracted with sodium hydroxide solution. Although the extraction yield of bixin using soybean oil was very low and decreased during the process, the total amount of extracted bixin still increased with the high value until the end of extraction. This was due to a large amount of bixin lost in the process, which reduced the pigment intensity of soybean oil extract. The percentages of bixin extracted from annatto seed with soybean oil were $40.2 \%$ and $67.4 \%$ (equivalent to 5.4 and $9.0 \mathrm{mg} / \mathrm{g}$ dried seeds) after 20 mins and at the end, respectively. In comparison with the

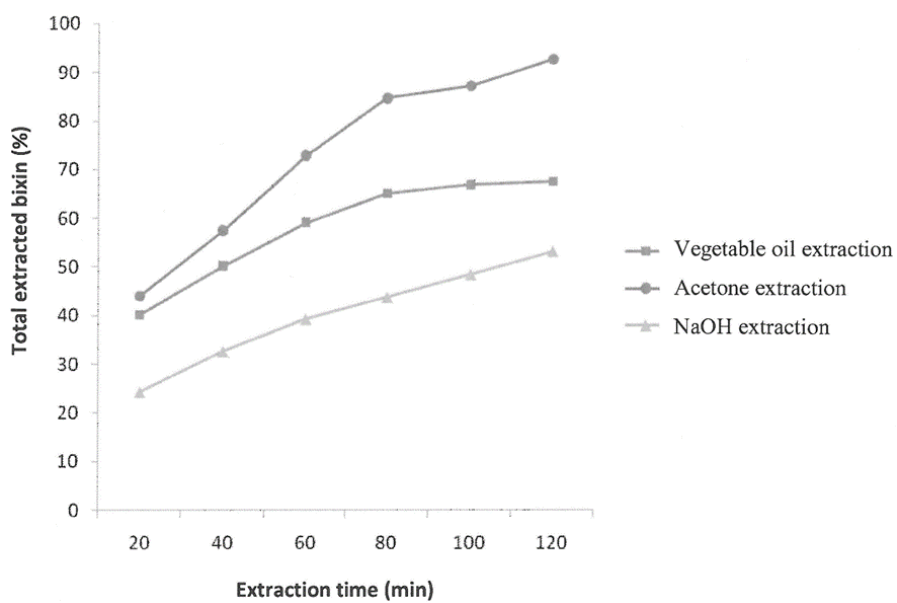

Figure 3. Total amounts of bixin from annatto seeds released into the solvents during the extractions with soybean oil, acetone and sodium hydroxide solution 
two other methods, extraction with sodium hydroxide solution achieved a significantly lower total extracted bixin, which increased slowly from $24.3 \%$ to only $53.1 \%$ (equivalent to $7.1 \mathrm{mg} / \mathrm{g}$ dried seeds).

\subsection{Toluene and m-xylene contents in annatto extracts}

The content of toluene in the extracts produced during the three extraction processes was quite low (Table 1). The level of this compound in the solutions extracted with acetone remained negligible throughout the extraction. The appearance of toluene in acetone extracts fluctuated from 1.25 to $3.73 \mathrm{mg} / \mathrm{L}$, and no significant differences were observed at different extraction times. Likewise, a very small amount of toluene was detected in soybean oil extracts. A significant increase of this compound was only observed between the first half $(3.65-4.35 \mathrm{mg} / \mathrm{L})$ and the second half $(6.45-7.25 \mathrm{mg} / \mathrm{L})$ of the process, but not between each point of time. Surprisingly, although sodium hydroxide extraction was carried out at a lower temperature $\left(50^{\circ} \mathrm{C}\right)$ compared to two other methods, the amount of toluene in these extracts was significantly higher, it was $11.10 \mathrm{mg} / \mathrm{L}$ after only $20 \mathrm{mins}$, and increased gradually to $18.25 \mathrm{mg} / \mathrm{L}$ at the end of the process.

As mentioned in some reports related to the degradation of bixin, $m$-xylene is the major volatile compound produced when bixin is decomposed (McKeown, 1963; Scotter et al., 2000). The results of this study also indicate significantly high levels of $\mathrm{m}$ xylene in the extracts (except for the sodium hydroxide extracts). The content of $m$-xylene produced in the extraction with acetone was very high even after only 20 mins (Table 2). However, it fluctuated at very high level $(90.74-110.58 \mathrm{mg} / \mathrm{L})$ during the process without a significant difference between the time points. In extraction using soybean oil, the level of $m$-xylene was quite low at the beginning $(10.67 \mathrm{mg} / \mathrm{L}$ for $20 \mathrm{~min})$, but it increased rapidly to $80.88 \mathrm{mg} / \mathrm{L}$ at $120 \mathrm{~min}$ of extraction. In contrast with the two above methods, the content of $m$-xylene remained constant, unchanged during extraction at considerably lower levels as compared to the content of toluene in sodium hydroxide extracts (Table 2).

Our results on the contents of $m$-xylene and toluene in the soybean oil extracts are in good agreement with the earlier studies of Scotter et al. (2000) and GalindoCuspinera et al. (2002), which showed very high levels of xylene and quite low contents of toluene in oil-soluble annatto extracts. The high amount of xylene matches well with the severe degradation of bixin during extraction at high temperatures with soybean oil. However, the low level of toluene, even in comparison with the sodium hydroxide extracts, could be due to the evaporation of this compound during extraction at $120^{\circ} \mathrm{C}$ (the boiling point of toluene is $110.6^{\circ} \mathrm{C}$ ). Similarly, the high temperature of this extraction might be responsible for the lower concentration of this $m$-xylene in soybean oil extracts in comparison with the acetone extracts, although the degradation of bixin in this method was much greater. The use of a Soxhlet extractor in the acetone extraction achieved a high extraction yield of bixin, but it prevented the release of m-xylene from the solution due to the condensation of this compound. As a result, the content of $m$-xylene in the acetone extracts was very high, even at the beginning of the process.

\section{Conclusion}

Traditional extraction of annatto (extraction with soybean oil) resulted in great degradation of bixin, such that bixin yield was very low even though the total amount of bixin released from annatto seeds into solution

Table 1. Concentration of toluene in annatto extracts during extractions with sodium hydroxide solution, soybean oil, and acetone $(\mathrm{mg} / \mathrm{L})$

\begin{tabular}{lcccccc}
\hline & \multicolumn{5}{c}{ Extraction time $(\mathrm{min})$} \\
\cline { 2 - 7 } & 20 & 40 & 60 & 80 & 100 & 120 \\
\hline $\mathrm{NaOH}$ extracts & $11.10 \pm 0.11^{\mathrm{a}}$ & $12.63 \pm 0.97^{\mathrm{b}}$ & $15.68 \pm 0.22^{\mathrm{c}}$ & $16.91 \pm 0.21^{\mathrm{d}}$ & $17.31 \pm 1.30^{\mathrm{de}}$ & $18.25 \pm 0.25^{\mathrm{e}}$ \\
Soybean oil extracts & $3.65 \pm 0.54^{\mathrm{a}}$ & $4.35 \pm 0.56^{\mathrm{a}}$ & $4.08 \pm 0.92^{\mathrm{a}}$ & $6.45 \pm 1.09^{\mathrm{b}}$ & $6.72 \pm 2.30^{\mathrm{b}}$ & $7.25 \pm 0.43^{\mathrm{b}}$ \\
Acetone extracts & $3.52 \pm 3.09^{\mathrm{a}}$ & $2.01 \pm 0.49^{\mathrm{a}}$ & $1.44 \pm 2.34^{\mathrm{a}}$ & $3.73 \pm 2.00^{\mathrm{a}}$ & $1.25 \pm 0.43^{\mathrm{a}}$ & $2.99 \pm 1.98^{\mathrm{a}}$ \\
\hline
\end{tabular}

Means with same superscript within each row are not significantly different $(\mathrm{p}<0.05)$.

Table 2. Concentration of $m$-xylene in annatto extracts during extractions with sodium hydroxide solution, soybean oil, and acetone $(\mathrm{mg} / \mathrm{L})$

\begin{tabular}{lcccccc}
\hline & \multicolumn{5}{c}{ Extraction time $(\mathrm{min})$} \\
\cline { 2 - 7 } & 20 & 40 & 60 & 80 & 100 & 120 \\
\hline NaOH extracts & $3.21 \pm 0.22^{\mathrm{a}}$ & $4.19 \pm 0.59^{\mathrm{ab}}$ & $4.46 \pm 0.99^{\mathrm{ab}}$ & $4.64 \pm 0.30^{\mathrm{b}}$ & $4.04 \pm 0.61^{\mathrm{ab}}$ & $3.60 \pm 1.24^{\mathrm{ab}}$ \\
Soybean oil extracts & $10.67 \pm 0.64^{\mathrm{a}}$ & $23.83 \pm 2.15^{\mathrm{b}}$ & $31.38 \pm 0.73^{\mathrm{c}}$ & $35.31 \pm 1.17^{\mathrm{d}}$ & $53.56 \pm 1.83^{\mathrm{e}}$ & $80.88 \pm 1.21^{\mathrm{f}}$ \\
Acetone extracts & $109.32 \pm 12.98^{\mathrm{a}}$ & $97.21 \pm 11.99^{\mathrm{a}}$ & $90.74 \pm 17.22^{\mathrm{a}}$ & $110.58 \pm 9.09^{\mathrm{a}}$ & $102.72 \pm 23.42^{\mathrm{a}}$ & $100.26 \pm 7.74^{\mathrm{a}}$ \\
\hline \multicolumn{2}{l}{ Means with same superscript within each row are not significantly different $(\mathrm{p}<0.05)}$.
\end{tabular}


was high. In addition, the content of $m$-xylene in the soybean oil extracts also rose rapidly to a high level. Although acetone extraction produced a high extraction yield, the high concentration of $m$-xylene in the extracts might lead to an important problem for annatto products manufactured by this method. Extraction with sodium hydroxide solution produced a small amount of volatile compounds with a low degradation of pigment, but the extraction yield of pigment was also quite low, which is not economically satisfactory for the production of annatto powder. These results suggest that it is necessary to develop methods to solve these weak points and exploit the advantages of the available extraction methods.

\section{Conflict of interest}

The authors declare no conflict of interest.

\section{References}

Balaswamy, K., Pamidighantam, P., Babu, P. and Akula, S. (2012). Application of annatto (Bixa orellena L.) dye formulations in Indian traditional sweetmeats: Jilebi and jangri. Indian Journal of Traditional Knowledge, 11(1), 103-108.

Balaswamy, K., Prabhakara Rao, P.G., Satyanarayana, A. and Rao, D.G. (2006). Stability of bixin in annatto oleoresin and dye powder during storage. LWT - Food Science and Technology, 39(8), 952956. https://doi.org/10.1016/j.lwt.2005.07.004

Barnett, B.M. (1957). Process for extracting the coloring matter from annatto seeds. US Patent 2815287. USA: United States Patent Office.

Galindo-Cuspinera, V., Lubran, M.B. and Rankin, S.A. (2002). Comparison of volatile compounds in waterand oil-soluble annatto (Bixa orellana L.) extracts. Journal of Agricultural and Food Chemistry, 50(7), 2010-2015. https://doi.org/10.1021/jf011325h

Glória, M.B.A., Vale, S.R. and Bobbio, P.A. (1995). Effect of water activity on the stability of bixin in an annatto extract-microcrystalline cellulose model system. Food Chemistry, 52(4), 389-391. https:// doi.org/10.1016/0308-8146(95)93287-2

Haila, K.M., Lievonen, S.M. and Heinonen, M.I. (1996). Effects of Lutein, Lycopene, Annatto, and $\gamma$ Tocopherol on Autoxidation of Triglycerides. Journal of Agricultural and Food Chemistry, 44(8), 2096-2100. https://doi.org/10.1021/jf9504935

Hoang, V.C, Hoi, N.T.N. and Eun, J.B. (2012). Improvement of bixin extraction yield and extraction quality from annatto seed by modification and combination of different extraction methods International Journal of Food Science and
Technology, 47(7), 1333-1338. https:// doi.org/10.1111/j.1365-2621.2012.02977.x

Junior, A.C., Asad, L.M., Oliveira, E.B., Kovary, K., Asad, N.R. and Felzenszwalb, I. (2005). Antigenotoxic and antimutagenic potential of an annatto pigment (norbixin) against oxidative stress. Genetics and Molecular Research, 4(1), 94-99.

McKeown, G. (1963). Composition of oil-soluble annatto food colours II. Thermal degradation of bixin. Journal of Association of Official Analytical Chemists, 46(5), 790-796. https://doi.org/10.1093/ jaoac/46.5.790

Montenegro, M.A., Rios Ade, O., Mercadante, A.Z., Nazareno, M.A. and Borsarelli, C.D. (2004). Model studies on the photosensitized isomerization of bixin. Journal of Agricultural and Food Chemistry, 52(2), 367-373. https://doi.org/10.1021/jf0349026

Najar, S.V., Bobbio, F.O. and Bobbio, P.A. (1988). Effects of light, air, anti-oxidants and pro-oxidants on annatto extracts (Bixa orellana). Food Chemistry, 29(4), 283-289. https://doi.org/10.1016/0308-8146 (88)90043-X

Prabhakara Rao, P.G., Jyothirmayi, T., Balaswamy, K., Satyanarayana, A. and Rao, D.G. (2005). Effect of processing conditions on the stability of annatto (Bixa orellana L.) dye incorporated into some foods. LWT - Food Science and Technology, 38(7), 779784. https://doi.org/10.1016/j.lwt.2004.08.015

Preston, H.D. and Rickard, M.D. (1980). Extraction and chemistry of annatto. Food Chemistry, 5(1), 47-56. https://doi.org/10.1016/0308-8146(80)90063-1

Quintero Quiroz, J., Celis Torres, A., Muñoz Ramirez, L., Silva Garcia, M., Ciro Gomez, G. and Rojas Camargo, J. (2019). Optimization of the MicrowaveAssisted Extraction Process of Bioactive Compounds from Annatto Seeds (Bixa orellana L.). Antioxidants, 8(2), 37. https://doi.org/10.3390/antiox8020037

Rahmalia, W., Fabre, J.F. and Mouloungui, Z. (2015). Effects of Cyclohexane/Acetone Ratio on Bixin Extraction Yield by Accelerated Solvent Extraction Method. Procedia Chemistry, 14, 455-464.

Reith, J.F. and Gielen, J.W. (1971). Properties of bixin and norbixin and the composition of annatto extracts. Journal of Food Science, 36(6), 861-864. https:// doi.org/10.1111/j.1365-2621.1971.tb15545.x

Scotter, M. (2009). The chemistry and analysis of annatto food colouring: a review. Food Additives and Contaminants: Part A, 26(8), 1123-1145. https:// doi.org/10.1080/02652030902942873

Scotter, M.J. (1995). Characterisation of the coloured thermal degradation products of bixin from annatto and a revised mechanism for their formation. Food 
Chemistry, 53(2), 177-185. https:// doi.org/10.1016/0308-8146(95)90785-6

Scotter, M.J., Castle, L. and Appleton, G.P. (2001). Kinetics and yields for the formation of coloured and aromatic thermal degradation products of annatto in foods. Food Chemistry, 74(3), 365-375. https:// doi.org/10.1016/S0308-8146(01)00135-2

Scotter, M.J., Wilson, L.A., Appleton, G.P. and Castle, L. (1998). Analysis of Annatto (Bixa orellana) Food Coloring Formulations. 1. Determination of Coloring Components and Colored Thermal Degradation Products by High-Performance Liquid Chromatography with Photodiode Array Detection. Journal of Agricultural and Food Chemistry, 46(3), 1031-1038. https://doi.org/10.1021/jf970063+

Scotter, M.J., Wilson, L.A., Appleton, G.P. and Castle, L. (2000). Analysis of Annatto (Bixa orellana) Food Coloring Formulations. 2. Determination of Aromatic Hydrocarbon Thermal Degradation Products by Gas Chromatography. Journal of Agricultural and Food Chemistry, 48(2), 484-488. https://doi.org/10.1021/jf9901845

Shuhama, I.K., Aguiar, M.L., Oliveira, W.P. and Freitas, L.A.P. (2003). Experimental production of annatto powders in spouted bed dryer. Journal of Food Engineering, 59(1), 93-97. https://doi.org/10.1016/ S0260-8774(02)00433-8

Sinha, K., Chowdhury, S., Saha, P.D. and Datta, S. (2013). Modeling of microwave-assisted extraction of natural dye from seeds of Bixa orellana (Annatto) using response surface methodology (RSM) and artificial neural network (ANN). Industrial Crops and Products, 41, 165-171. https://doi.org/10.1016/ j.indcrop.2012.04.004

Smith, J. (2006). Annatto extracts. Chemical and technical assessment. Retrieved on the September 30, 2020 from Food and Agriculture Organization of the United Nations website: http://www.fao.org/3/aat973e.pdf.

Soumya, V., Venkatesh, P., Kothandam, H.P. and Shrishailappa, B. (2010). Microwave facilitated extraction of bixin from Bixa orellana and it's invitro antioxidant activity. Der Pharmacia Lettre, 2 (2), 479-485.

Taham, T., Cabral, F.A. and Barrozo, M.A.S. (2015). Extraction of bixin from annatto seeds using combined technologies. The Journal of Supercritical Fluids, 100, 175-183. https://doi.org/10.1016/ j.supflu.2015.02.006

Yolmeh, M., Habibi Najafi, M.B. and Farhoosh, R. (2014). Optimisation of ultrasound-assisted extraction of natural pigment from annatto seeds by response surface methodology (RSM). Food Chemistry, 155, 319-324. https://doi.org/10.1016/ j.foodchem.2014.01.059 